\title{
Illuminating Medulloblastoma
}

\section{Visualising a novel route of medulloblastoma metastasis using 3D animation}

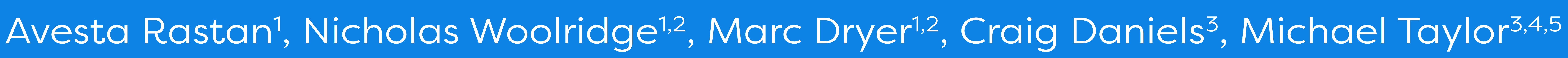

Biomedical Communications, University of Toronto; ${ }^{2}$ Department of Biology, University of Toronto; ${ }^{3}$ Arthur and Sonia Labatt Brain Tumour Research Centre;
${ }^{4}$ Developmental and Stem Cell Biology, Hospital for Sick Children; ${ }^{5}$ Department of Laboratory Medicine and Pathobiology, University of Toronto

\section{Abstract}

Medulloblastoma, a childhood brain cancer of the cerebellum, has one of the highest mortality rates of pediatric cancers. For over a century, scientists believed that medulloblastoma metastasized exclusively through cerebrospinal fluid; however, novel research reveals that it can also spread through the circulatory system. Understanding this new mechanism is critical for the development of therapies and to help affected families understand their child's disease. An educational 3D animation was developed to effectively disseminate this research to the scientific community and to educate physicians, researchers, and affected families about this disease.

\section{Introduction}

The hematogenous route of medulloblastoma metastasis presents the first biological target for metastases. Considering that

metastases are the leading cause of treatment failure and death in medulloblastoma patients ${ }^{2}$, the dissemination of this research is critical to the development of new therapies. The main problem is that the scientific community is largely unaware of this research. Additionally, scientific discoveries are often inaccessible to non-specialists, including patients and their families. Animation is an effective tool for the dissemination of research findings to the community and can be highly effective at increasing interest in scientific information ${ }^{3,4}$. A variety of visual design strategies and storytelling techniques can be used to develop said animation.

Communication Objectives

1) Educate

Compare metastasis via CSF vs. newly discovered route

$\begin{array}{ll}3) \text { Establish Context } & \text { 4) Evoke Emotion }\end{array}$

Load Use visual design strategies to long-term memory retention Use of visual metaphor will put the Employ storytelling and cinematic why this research matters, what the inspire the audience future implications are, and how it is relevant to the audience

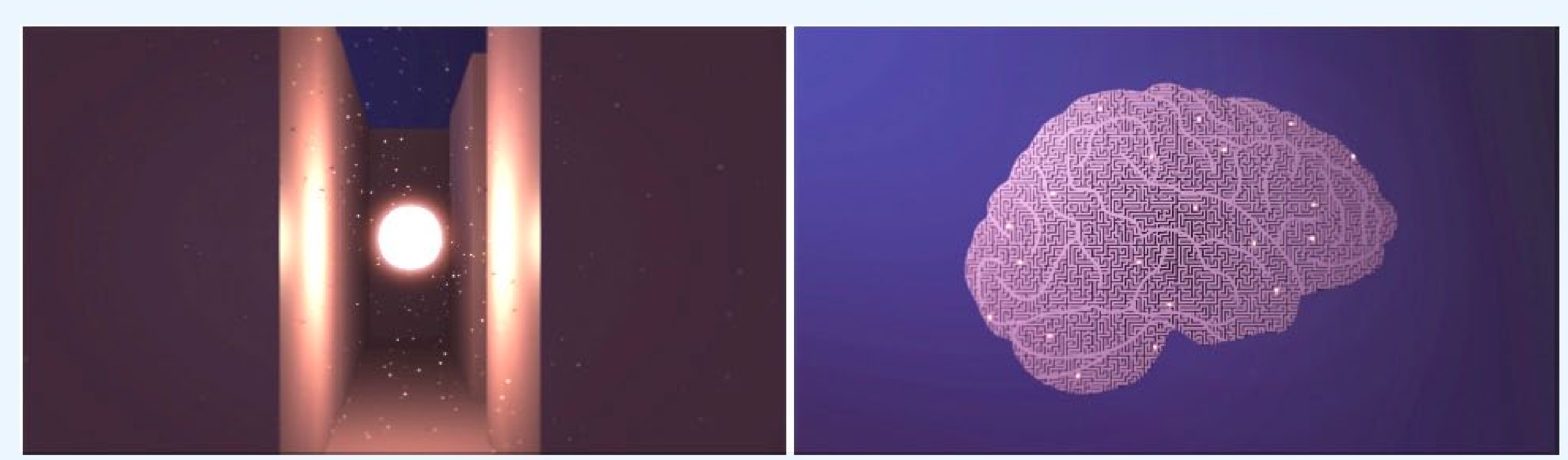

Figure 1. Visual metaphor can establish context and help the audience empathise with the journey of scietention. The sci, mafic methed is visulized personal and us through the maze of the "unknown." This shows the audience how scientific research helps us navigate and make sense of the world around us.

\section{Materials \& Methods}

Timeline \& Software

May, 2018

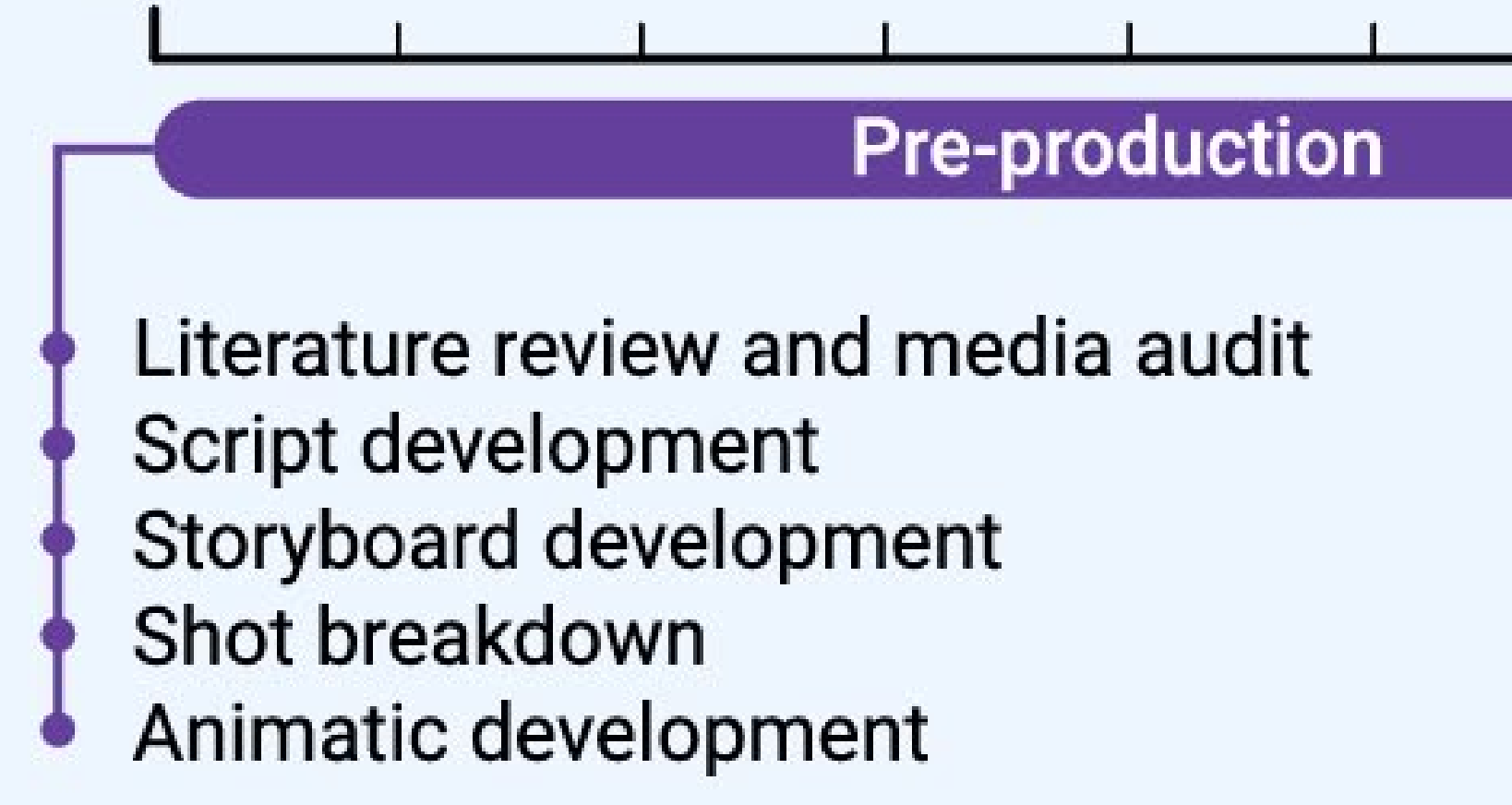

January, 2019 $\stackrel{\text { July, } 2019}{\longrightarrow}$

Software Used: Procreate, Photoshop, Illustrator, Excel, ZBrush, UCSF Chimera, NeuronBuild, Molecular Maya, Autodesk Maya, After Effects, Premiere Pro, Audition

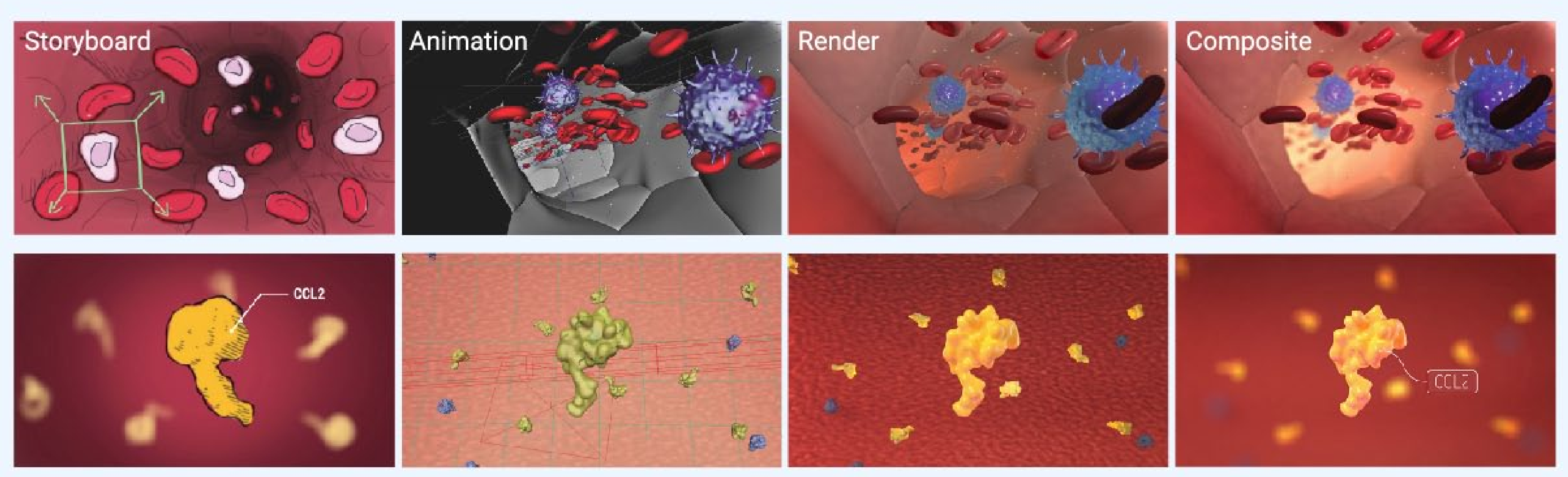

Figure 2. Two sample shots from pre-production to post-production. Images from the storyboard were composited in After Effects.

Linear Storytelling

Linear storytelling will be used for knowledge-scaffolding and to allow the audience to easily follow the flow of information.

$\begin{array}{ccc}\begin{array}{c}\text { Outline medulloblastoma } \\ \text { background information }\end{array} & \begin{array}{c}\text { Introduce the new route of } \\ \text { medulloblastoma metastasis } \\ \text { and compare the two routes }\end{array} & \begin{array}{c}\text { Emphasize the future implications } \\ \text { of this discovery and the need for } \\ \text { more research }\end{array}\end{array}$

Visual Design Strategies

\begin{tabular}{|l|l|l|}
$\begin{array}{l}\text { Cinematic atmosphere } \\
\text { - Create realistic environments } \\
\text { with anatomical accuracy } \\
\text { - Use of lighting and colour to } \\
\text { establish the mood }\end{array}$ & $\begin{array}{l}\text { Visuospatial contiguity } \\
\text { - Make verbal and visual com- } \\
\text { ponents cohesive } \\
\text { - Use sound effects to make ac- } \\
\text { tions more convincing }\end{array}$ & $\begin{array}{l}\text { Visual metaphor } \\
\text { - Use of metaphor to establish } \\
\text { the context of this research } \\
\text { - Metaphor can help the audi- } \\
\text { ence relate to the material }\end{array}$ \\
\hline $\begin{array}{l}\text { Attention-cueing } \\
\text { - Make important object salient } \\
\text { - using colour, opacity, DOF, etc. } \\
\text { ase of graphic elements such } \\
\text { as arrows, labels, and text }\end{array}$ & $\begin{array}{l}\text { Colour-coding } \\
\text { - Use colour to help identify ob- } \\
\text { jects and achieve consistency } \\
\text { - Use a colour scheme to make } \\
\text { the animation cohesive and } \\
\text { add its own unique style }\end{array}$ & $\begin{array}{l}\text { Representation style } \\
\text { - Create realistic elements to } \\
\text { improve learning outcomes } \\
\text { - Use 2D elements at appropri- } \\
\text { ate times }\end{array}$ \\
$\begin{array}{l}\text { Narrative } \\
\text { - Develop a conversational nar- } \\
\text { rative directed to the audience }\end{array}$ & $\begin{array}{l}\text { Pacing } \\
\text { - Use system-pacing to } \\
\text { increase learning outcomes } \\
\text { - Record with high-quality } \\
\text { equipment }\end{array}$ & $\begin{array}{l}\text { Evoke emotion } \\
\text { - Make it personal so the audi- } \\
\text { ence can relate } \\
\text { - Use music at key moments to facilitate }\end{array}$ \\
\hline
\end{tabular}

\section{Results}

The resulting animation is around 4 minutes in length and will be presented by SickKids Hospital at conferences, grant panels, and on the Taylor Lab website for physicians, researchers and graduate students. It will also be uploaded to YouTube and Vimeo for educational outreach, non-profit use, and distrubution to patients.

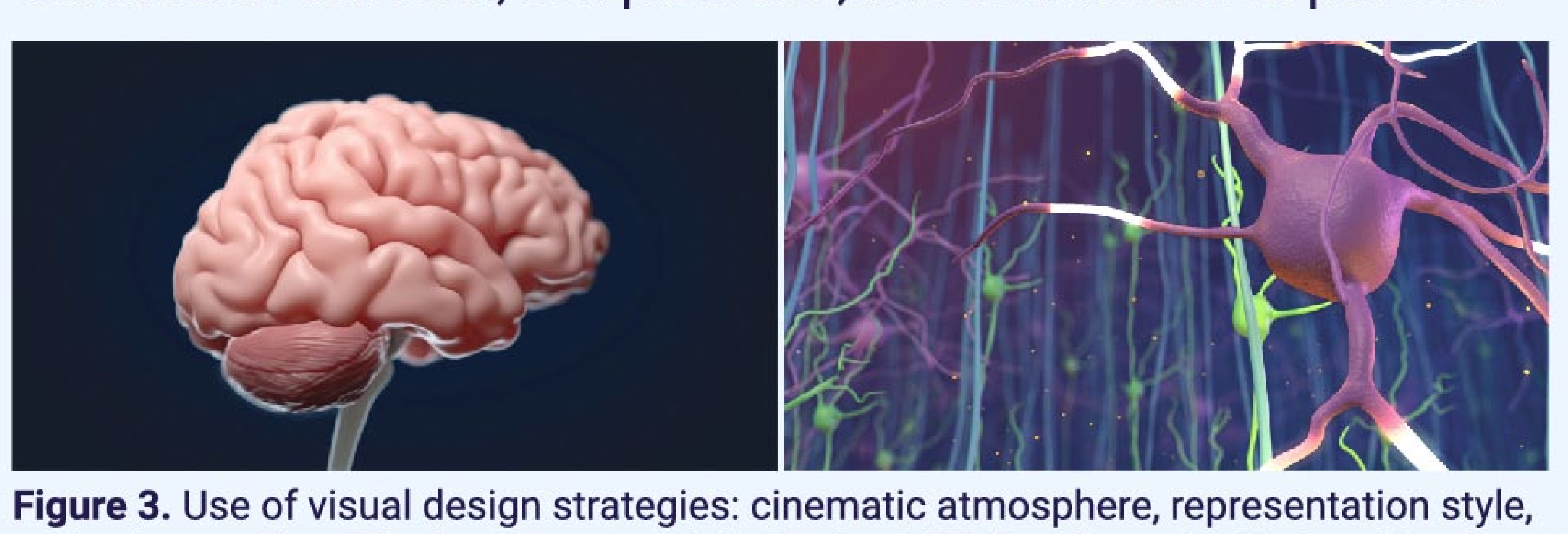

Figure 3. Use of visual design strategies: cinematic atmosphere, representation style, and colour-coding. The brain was modelled using MRI data from the Natonal to
for Health $(\mathrm{NIH})$. Real morphology data from NeuroMorpho was used to create accurate cereballar neurons. Cinematic atmosphere was established using dramatic lighting, dust particles, and depth of field (DOF).
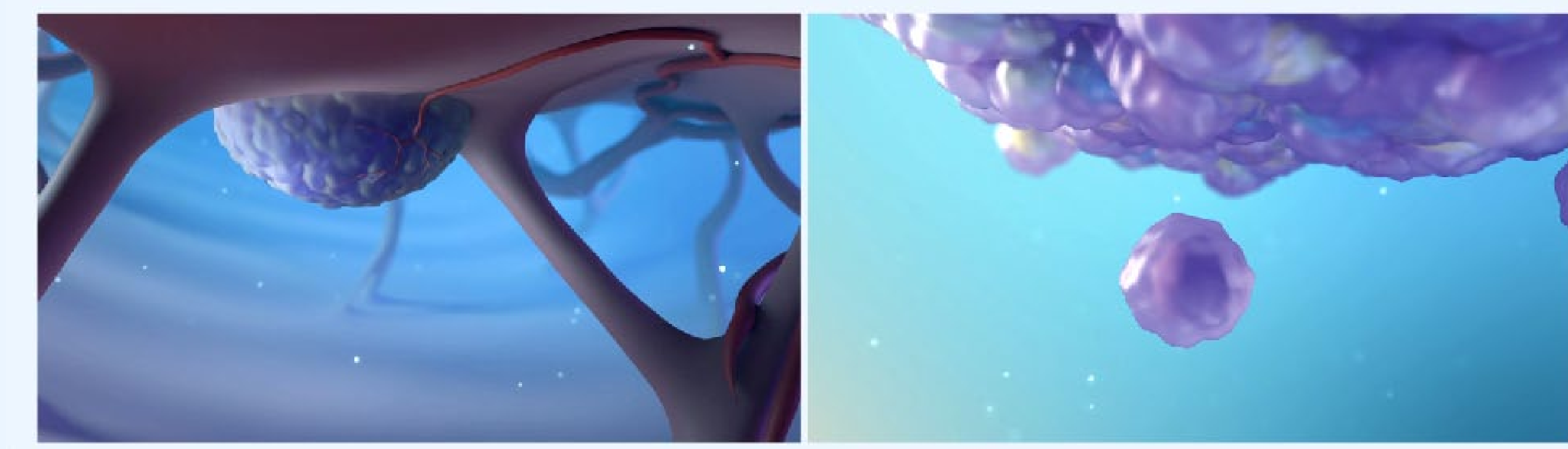

igure 4. Use of visual design strategies: cinematic atmosphere, visuospatial contiguity, representation style, and colour-coding. Underwater sounds were used to enhance the feeling of being immersed in CSF in the leptomingeal space. Tumour cells were coloured similarly so that it is easy to identify them; their nuclei were
coloured differently to represent cancer heterogeneity.

\section{Conclusions}

successfully developed a 3D animation to disseminate novel medulloblastoma research; this was achieved using various visual design strategies and linear storytelling. It serves as the first visual resource of its kind that educates a lay audience about the two mechanisms of medulloblastoma metastasis. Through the accurate depiction of anatomical and molecular structures, cinematic style, and innovative use of visual metaphor, a lay audience can effectively learn about this research and its future implications in the development of novel cancer therapeutics.

\section{References}

Bibliography

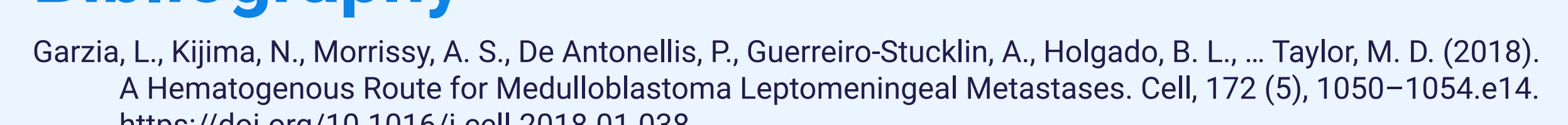

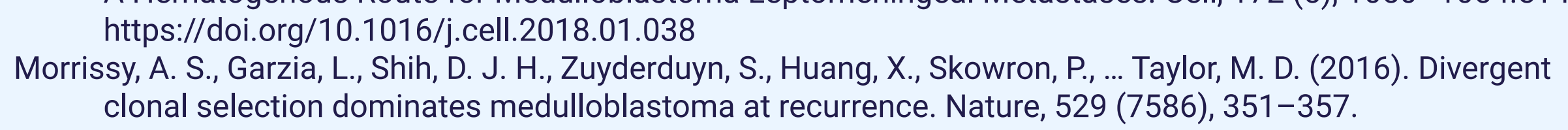

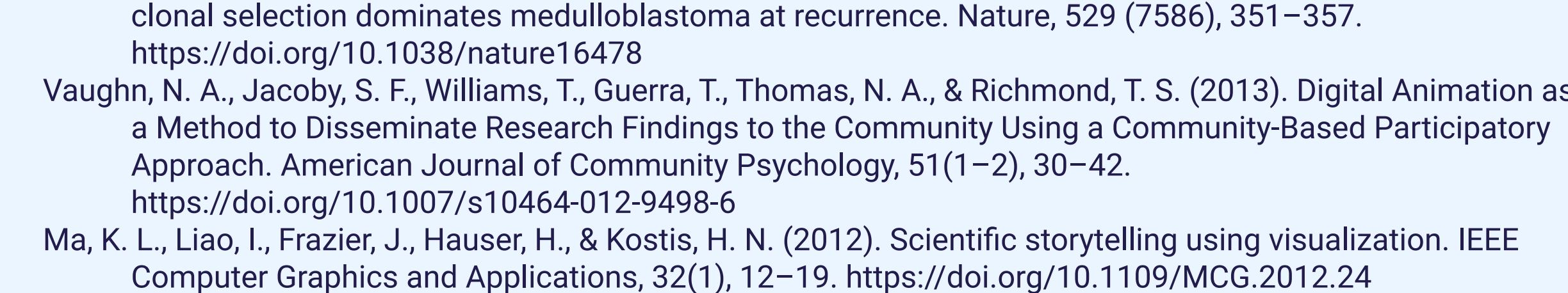

